\title{
Associations between several aspects of heifer development and dairy cow survivability to second lactation
}

\author{
A. Bach $^{1}$ \\ Institució Catalana de Recerca i Estudis Avançats (ICREA), Barcelona, Spain, and Department of Ruminant Production, Institut de Recerca \\ i Tecnologia Agroalimentàries (IRTA), 08140 Caldes de Montbui, Spain
}

\begin{abstract}
A data set from 7,768 Holstein heifers born between 2004 and 2006, including growth rates from birth until first calving; age and body weight at insemination; and incidence of diarrhea, navel infections, and bovine respiratory disease (BRD) was used to evaluate potential associations between these factors and the odds of completing the first lactation. All heifers were raised in a contract heifer operation (Rancho Las Nieves, Mallen, Spain) and returned to their herds of origin (133 herds in total) before calving. Dates of death were provided by the Subdirección General de Explotaciones y Sistemas de Trazabilidad de los Recursos Agrícolas y Ganaderos from the Ministry of Environment, and Rural and Marine Areas of the Spanish government. At the time of analysis, 2,571 (33.1\%) animals out of the 7,768 considered had died. In total, $655(8.4 \%)$ heifers did not finish first lactation, and $31.5 \%$ of these left the herd within the first 50 DIM. Also, $4.8 \%$ of heifers aborted and were rebred. Data were analyzed using a mixed-effects logistic regression and survival analysis for dichotomous variables and a mixed-effects model for continuous ones. Incidence of diarrhea or navel infection was not associated with the chances of finishing the first lactation. Heifers that completed first lactation had a lesser average age at first calving $(724 \pm 2 \mathrm{~d})$ than those that did not $(737 \pm 3 \mathrm{~d})$. Heifers that reached second lactation grew $(0.8 \pm 0.04 \mathrm{~kg} / \mathrm{d})$ more between 12 and $65 \mathrm{~d}$ of age than those that did not $(0.7 \pm 0.04$ $\mathrm{kg} / \mathrm{d}$ ). As conception rate decreased, chances of leaving the herd before completing the first lactation increased. The number of AI services needed per conception as a nulliparous heifer was negatively associated with survivorship to second lactation. Heifers that experienced an abortion were $2.73 \pm 0.52$ times more likely to leave the herd before completing the first lactation (but also calved with a much older age at first calving). Heifers that experienced 4 or more BRD cases before first calv-
\end{abstract}

Received July 19, 2010.

Accepted October 27, 2010.

${ }^{1}$ Corresponding author: alex.bach@irta.es ing had $1.87 \pm 0.14$ greater odds of not completing the first lactation than those that never experienced BRD. These results show potential to forecast future heifer success in finishing the first lactation based on average daily gain early in life, incidence of $\mathrm{BRD}$, reproductive performance (conception and abortion rates), and age at first calving.

Key words: bovine respiratory disease, culling, growth, survival

\section{INTRODUCTION}

Rearing heifers represents about $20 \%$ of total milk production costs (Donovan et al., 1986; Fetrow, 1988), and the return on the investment allocated from birth to first lactation is commonly not fully recovered until at least the end of first lactation. Therefore, future productive life span of heifers is an important factor in determining profits of dairy enterprises.

Voluntary culling decisions based on profit consist of substituting a cow with a replacement on the basis that the latter is expected to be more profitable and not because the cow being replaced was not profitable (Lehenbauer and Oltjen, 1998). Congleton (1988) indicated that allocating individual predicted milk performance on each replacement would improve the economic outcome of culling decisions. However, if the expected longevity of a replacement is not attained, then it is likely that the forecast milk performance would not be fulfilled, rendering a culling decision either unprofitable or less profitable than initially expected. In the United States, Hare et al. (2006) reported a decline of $4 \%$ in annual survival rates of first-lactation cows from 1980 to 1998. Therefore, allocating success probabilities to a heifer life's expectancy might contribute to improving the success of the replacement program. In addition, the possibility of forecasting future survival rate of a heifer early in life may spare unprofitable investment in a particular animal and recover part of the expenses in the meat rather than the milk market. Therefore, the objective of this study was to evaluate the potential association between development characteristics, health, and reproductive performance of replacement 
heifers with the odds of completing their first lactation as cows.

\section{MATERIALS AND METHODS}

Data regarding BW (at approximately 12, 65, 105, 150, 230, 310, 400, and $650 \mathrm{~d}$ of life), incidence of bovine respiratory disease (BRD), digestive upsets, navel infections, and reproductive history (conception rate and abortion) of 7,992 Holstein heifers born between January 2004 and December 2006, raised in a contract heifer operation in Spain (Rancho Las Nieves, Mallén) were matched with dates of death obtained from the Subdirección General de Explotaciones y Sistemas de Trazabilidad de los Recursos Agrícolas y Ganaderos from the Ministry of Environment, and Rural and Marine Areas of the Spanish government. At $650 \mathrm{~d}$ of life, heifers returned to their farms of origin, a total of 133 different herds. A total of 224 heifers (2.8\%) died or were culled before first calving, and these data were removed from the data set leading to a total of 7,768 records corresponding to heifers that reached first calving. In total, $372(4.8 \%)$ heifers aborted and were rebred; 2,571 heifers (33.1\%) died or were culled out of the 7,768 animals considered; and 655 heifers (8.4\%) did not finish the first lactation, and out of these, 206 (31.5\% of those leaving the herd during the first lactation) left the herd within the first 50 DIM. More than $55 \%$ of the heifers reached third lactation, and about $70 \%$ reached second lactation.

Days alive were calculated by difference between birth and death dates. The proportion of productive days over lifetime was calculated by dividing accumulated DIM by the last recorded age for each animal (corresponding to either death or termination of data collection period). The number of AI services required to achieve pregnancy as a nulliparous heifer was classified into an ordinal variable with values equal to 1,2 , 3,4 , and $\geq 5$ (with the latter class grouping more than 4 AI services per pregnancy). Similarly, the number of BRD that a particular heifer experienced also was classified using an ordinal variable with values equal to $1,2,3$, and $\geq 4$ (with the latter class grouping 4 and more BRD cases/heifer). For a BRD to be considered new, it had to occur at least $10 \mathrm{~d}$ after a previous one. Body weight precalving was estimated by assigning each individual ADG from 400 to $650 \mathrm{~d}$ of life to the remaining period of gestation until calving date. Last, animals were classified using 2 binomial variables as having had or not a diarrhea or a navel problem during the rearing process.

A mixed-effects logistic regression analysis was conducted to determine the effect of abortion on cow sur- vivability to second lactation (a binary variable) using Stata (Stata/SE 10.1 for Macintosh, StataCorp, College Station, TX). The random part of the model accounted for the categorical effects of farm of origin (and return) and birth year, and the fixed part of the model accounted for the effect of abortion (2 categories). In addition, a mixed-effects survival analysis based on the Weibull distribution with censoring was conducted to determine the effect of abortion (2 categories) on cow survivorship during first lactation using the JM (survival plus mixed-effects analyses) package (Rizopoulos, 2010) for R (available at http://www.R-project.org; R Development Core Team, Vienna, Austria). Censoring consisted of creating a binary classifying variable that would indicate whether the last observation for any particular animal was due to the death of the animal (would take value 1) or it was due to termination of the study (would take value 0) to reflect the uncertainty about the actual time of death (Crawley, 2007). The random part of the model accounted for the categorical effects of farm of origin (and return) and birth year, and the fixed part of the model accounted for the effect of abortion (a dichotomous variable).

After having assessed the effect of an abortion on survivorship, all data referring to heifers that underwent an abortion $(\mathrm{n}=372)$ were removed from the data set (to avoid potential bias in the analyses). Then, a mixed-effects logistic regression analysis was used to determine the effect of calving season (4 categories), BRD (5 categories), diarrhea (2 categories), navel infections (2 categories), or reproductive performance (5 categories) on cow survivability onto second lactation (a binary variable) following the same model described above. Also, a mixed-effects survival analysis with censoring was conducted to determine the effect of several discrete variables (referring to reproductive and health data) on cow survivorship curves using the JM (survival plus mixed-effects analyses) package (Rizopoulos, 2010) for R (available at http://www.R-project.org; R Development Core Team, Vienna, Austria) as described above.

Last, heifers were categorized using a binary variable as having completed or not first lactation, and then continuous variables, such as average age at first calving (AFC), BW at breeding, BW at calving, and ADG at different stages of development were analyzed using a mixed-effects model with farm of origin (and return) and year of birth as categorical random effects, and calving season (4 categories) and the binary variable (completed or not the first lactation) as fixed effects. This analysis was performed with SAS (v. 8.02, SAS Institute, Cary, NC). All dependent data were checked to fit a normal distribution using the Shapiro-Wilk test 
Table 1. Odds ratios of finishing first lactation in function of calving season with respect to calvings that occurred in summer

\begin{tabular}{lccc}
\hline Season & $\begin{array}{c}\text { Odds } \\
\text { ratio }\end{array}$ & SE & $P$-value \\
\hline Fall & 1.05 & 0.121 & 0.639 \\
Winter & 1.25 & 0.142 & 0.045 \\
Spring & 1.37 & 0.166 & 0.006 \\
\hline
\end{tabular}

(Shapiro and Wilk, 1965), and BW at breeding had to be log-transformed to achieve a normal distribution prior analysis.

\section{RESULTS AND DISCUSSION}

All data used in these analyses were observational; thus, only associations, not causality, should be drawn from this study.

Whether heifers finished the first lactation was associated $(P<0.01)$ with calving season. Heifers that calved in winter or spring had 1.25 and 1.37 greater $(P<0.05)$ odds of finishing the first lactation than those calving in summer and in fall, respectively (Table 1). Similarly, the survival analysis indicated that survivorship during first lactation was greatest $(P<0.05)$ for heifers born in winter and spring than for those born in summer and fall (data not shown). However, no association was found between calving season and the stage of lactation when heifers left the herd. These results are different than those reported by Pinedo and De Vries (2010), who described lower culling risks of cows that calved in winter and fall than in spring and summer. However, in the Pinedo and De Vries (2010) study, only cows of second lactation or older were considered, and thus carry-over effects of the rearing period on first-lactation animals could not be evaluated.

Average AFC ranged between 662 and 1,048 d. Most heifers $(95 \%)$ calved before $810 \mathrm{~d}$ of age, and those above $810 \mathrm{~d}$ had an abortion. Heifers that completed the first lactation had a lesser $\left(\mathrm{R}^{2}=0.14 ; P<0.05\right)$ average AFC $(724.3 \pm 2.3 \mathrm{~d})$ than those that did not (737.4 \pm 3.4 d). Van Amburgh et al. (1998) reported a $5 \%$ reduction in $4 \% \mathrm{FCM}$ in heifers that calved at 21.3 mo compared with those that calved at $24.5 \mathrm{mo}$, but the authors attributed the decrease in milk production to a lower BW of heifers calving at 21.3 mo and not to a direct effect of AFC. A more recent study (Ettema and Santos, 2004) reported that heifers that calved at $\leq 700 \mathrm{~d}$ of age produced less milk than those calving later, with the greatest producers being those calving at $\geq 751 \mathrm{~d}$ of age. From the analysis in the current study, it could be concluded that an AFC as early as $662 \mathrm{~d}$ (21.7 mo) is not associated with compromised future cow survivorship, and that as average AFC increases, survivorship decreases. In agreement with these results, a study conducted in the late 1980s involving 502 animals (Lin et al., 1988) reported that $66 \%$ of heifers that were bred at $350 \mathrm{~d}$ of age reached second lactation, whereas $62.7 \%$ of heifers bred at $462 \mathrm{~d}$ of age reached second lactation.

Average daily gain during the first $2 \mathrm{mo}$ of life was linked $\left(\mathrm{R}^{2}=0.23 ; P<0.05\right)$ with survivability to second lactation. Heifers that reached second lactation grew more $(0.8 \pm 0.04 \mathrm{~g} / \mathrm{d})$ than those that did not $(0.7$ $\pm 0.04 \mathrm{~kg} / \mathrm{d}$ ) between 12 and $65 \mathrm{~d}$ of age. Gardner et al. (1988) reported a positive, although nonsignificant, relationship between ADG and future milk yield, but no relationship with longevity was found. No relationships were found between BW at calving or BW at breeding with survivability to second lactation. However, a positive tendency $\left(\mathrm{R}^{2}=0.18 ; P=0.06\right)$ was found between ADG from $12 \mathrm{~d}$ of age until breeding on survivability (mostly due to the significant effect of the first $2 \mathrm{mo}$ of age), but no effect was found between ADG after breeding and survivability to second lactation.

In the current data set, a $4.8 \%$ abortion rate was observed. Heifers that experienced an abortion were 2.73 \pm 0.52 times more likely $(P<0.001)$ to leave the herd before completing the first lactation, and they were 2.11 \pm 0.52 times more likely $(P<0.001)$ to do it during the first 50 DIM than those that did not. Figure 1 shows that survivorship of heifers that had experienced an abortion was lower $(P<0.05)$ than that of heifers that

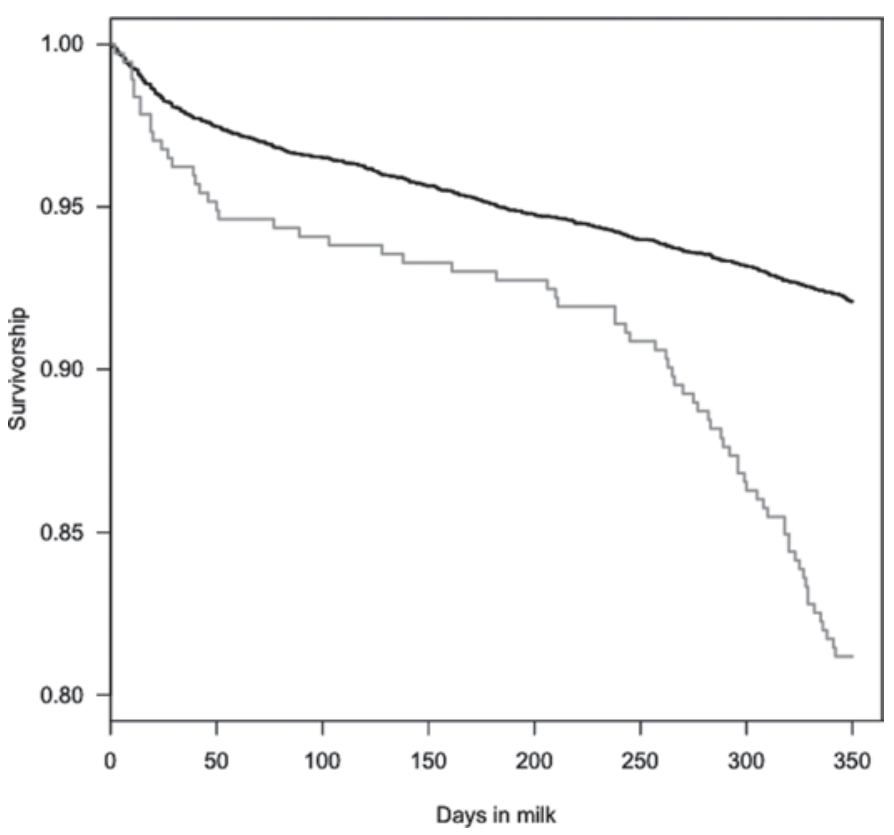

Figure 1. Evolution of survivorship throughout first lactation as influenced by the occurrence of an abortion before first calving. Black line $=$ did not abort; gray line $=$ had 1 abortion . 


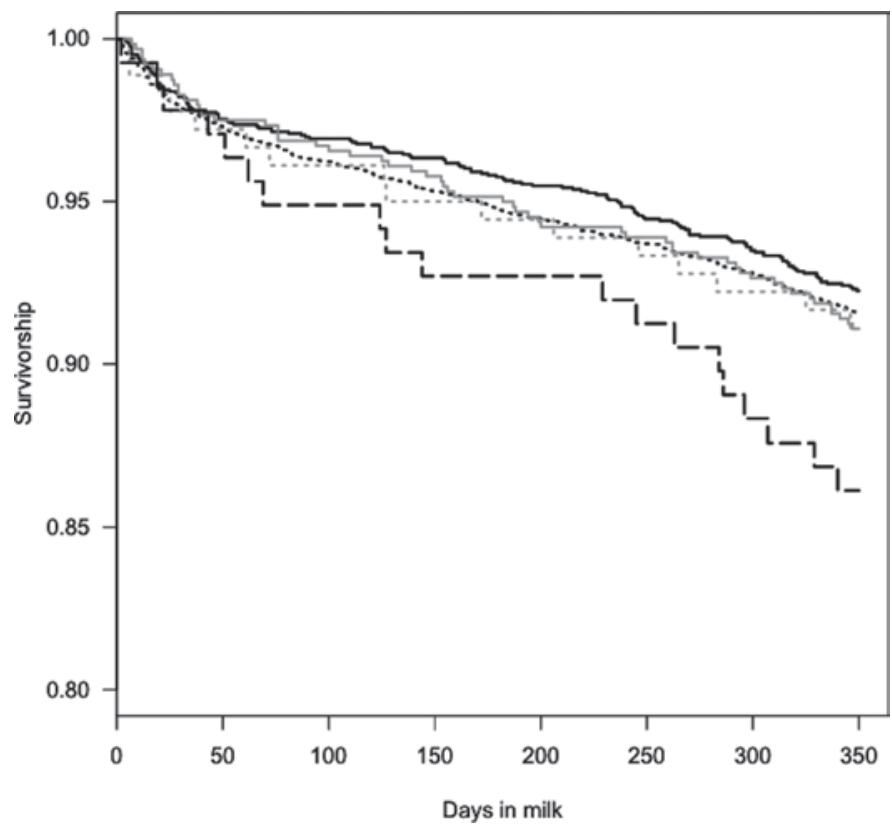

Figure 2. Evolution of survivorship throughout first lactation as influenced by the number of bovine respiratory (BRD) episodes experienced before first calving. Curves indicate the number of BRD cases: solid black line $=0$; solid gray line $=1$; dotted black line $=2$, dotted gray line $=3$, dashed black line $=\geq 4$.

did not incur an abortion. In addition, the scale factor of the survival analysis (2.19) indicated that the odds of being culled (or dying) greatly increased with DIM. However, heifers that aborted had an average AFC of $853 \mathrm{~d}$, whereas those that did not had an average AFC of $720 \mathrm{~d}$; thus, the effects of abortion and AFC were confounded. Removal of data corresponding to heifers that aborted from the dataset allowed separation of the effects of AFC and abortion. When data from heifers that aborted were removed, the AFC continued to show a negative relationship $(P<0.05)$ with survivorship (as described above) and when average AFC was evaluated only on heifers that had aborted also continued to be significantly $(P<0.05)$ and negatively associated with survivorship.

Incidence of diarrhea, $\mathrm{BRD}$, or navel infection was not associated with changes in the odds of finishing first lactation. Similarly, the number of diarrhea upsets was not associated with survivability. However, heifers that experienced 4 or more BRD cases before first calving had $1.87 \pm 0.14$ greater $(P<0.05)$ odds of not completing first lactation than those that had no BRD incidence before calving. Similarly, the survival analysis indicated that having 4 or more BRD cases had a negative effect $(P<0.05)$ on survivorship through first lactation, with heifers experiencing 1,2 , or 3 BRD cases also tending $(P<0.10)$ to show a decreased survivorship through first lactation (Figure 2). Furthermore, accumulated DIM of cows throughout recorded productive life and the proportion of productive days with respect to recorded days of life decreased linearly $(P<$ $0.05)$ as the number of BRD increased (Figure 3). Britney et al. (1984) conducted a study involving 460 calves from 2 institutional herds over a 7 -yr period and found no significant difference in milk production during first lactation between animals with no history of BRD and those with previous cases of BRD. However, Rossini (2004) reported a weak trend between number of BRD cases and milk production during first lactation and described a significant delay in average AFC as number of BRD cases increased. In the current study, a similar delay $(P<0.05)$ also was found, with heifers with no BRD having an average AFC of $724 \pm 2 \mathrm{~d}$ and those with 4 or more BRD cases showing an average AFC of $732 \pm 3 \mathrm{~d}$. However, contrary to the confounding effect encountered between abortion and average AFC, the confounding effect between average AFC and BRD could be directly addressed by running a mixed-effects logistic model that accounted for BRD, AFC, and their 2 -way interaction. The 3 parameters were significant, with the interaction indicating reduced survival odds for heifers that had 4 or more BRD cases and a delayed average AFC than those that had a delayed AFC and a low incidence of BRD.

Last, whether a cow would complete first lactation was associated $(P<0.001)$ with heifer conception rate. Nulliparous heifers that required 1 AI service had

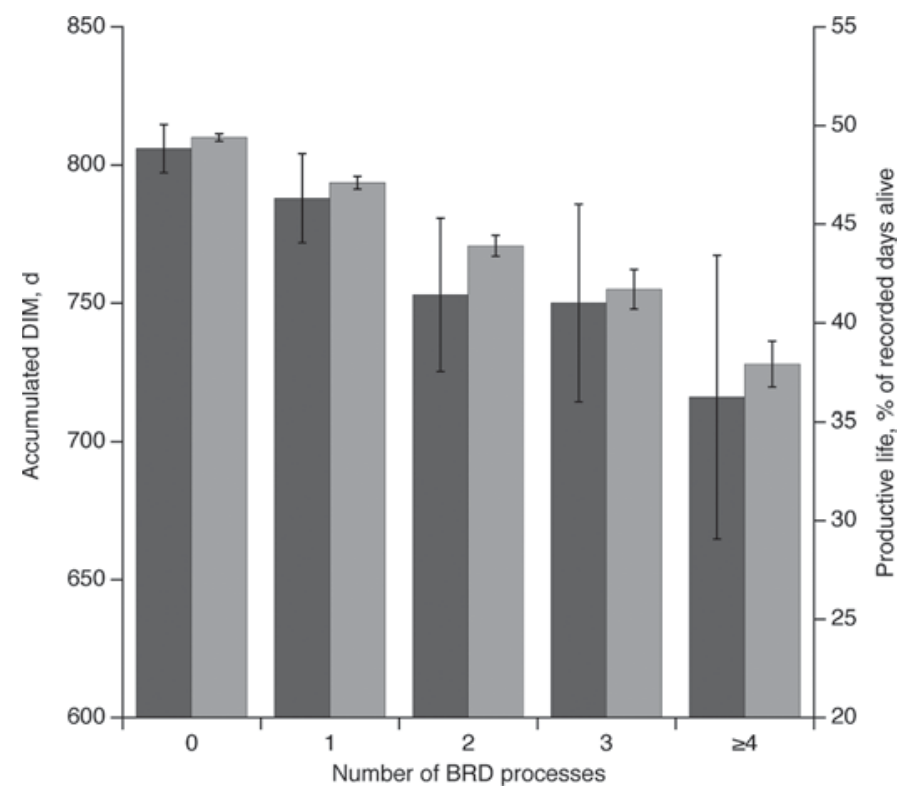

Figure 3. Accumulated DIM (dark bars) and productive life (as a proportion of productive days out of those recorded as alive; light bars) of cows as affected by the number of bovine respiratory disease (BRD) processes experienced before first calving. Error lines depict standard errors. 
Table 2. Odds ratios of finishing first lactation in function of the number of AI required per pregnancy with respect to heifers with a $100 \%$ conception rate

\begin{tabular}{lccc}
\hline $\begin{array}{l}\text { Number of } \\
\text { AI/pregnancy }\end{array}$ & $\begin{array}{l}\text { Odds } \\
\text { ratio }\end{array}$ & SE & $P$-value \\
\hline 2 & 0.74 & 0.073 & 0.002 \\
3 & 0.67 & 0.091 & 0.003 \\
4 & 0.65 & 0.122 & 0.02 \\
$\geq 5$ & 0.48 & 0.09 & $<0.001$ \\
\hline
\end{tabular}

the greatest chance to complete first lactation and as conception rate decreased, chances of leaving the herd before completing first lactation increased (Table 2). Also, cows that completed first lactation had a greater $(P<0.01)$ conception rate at first service $(60.3 \pm$ $1.8 \%)$ than those that did not $(50.7 \pm 2.6 \%)$. Although the reason why cows left the herd was not known, it is worth noting that most $(72.6 \%)$ heifers that had a poor reproductive performance (i.e., more than $3 \mathrm{AI}$ services/pregnancy) when young left the herds after 50 DIM as cows. In addition, the survival curve (Figure 4) shows that heifers that required more than 4 AI services were culled (or died) more aggressively than the other cows after approximately 100 DIM, which would indicate that the reason for leaving the herd might have probably been associated with poor milk yield.

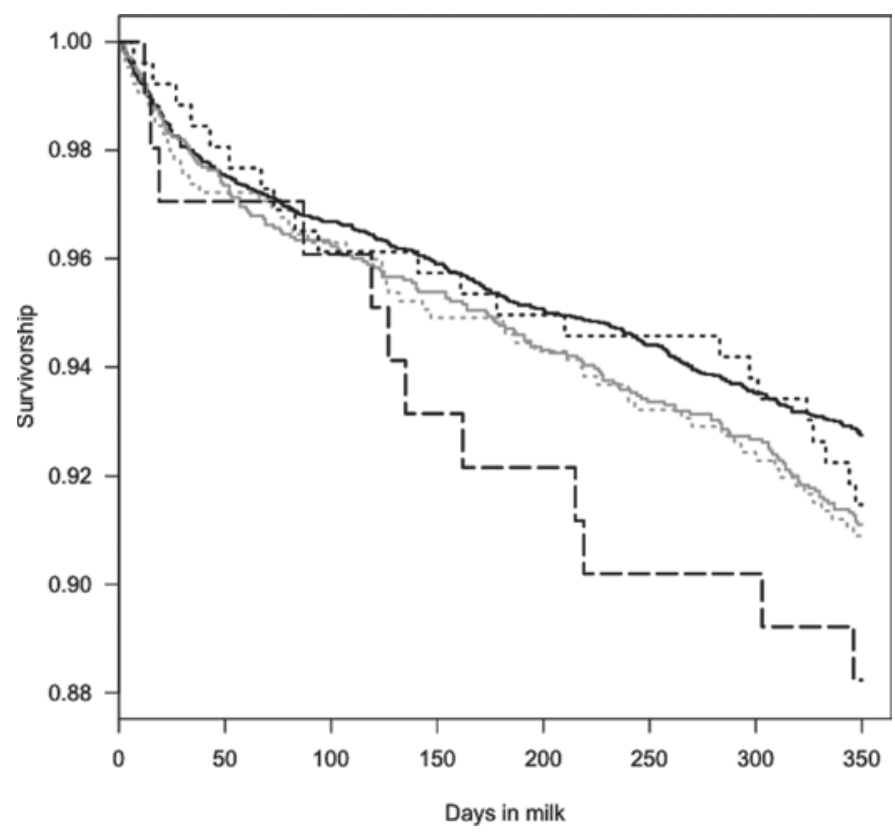

Figure 4. Evolution of survivorship throughout first lactation as influenced by the number of services needed to become pregnant as heifers. Curves indicate the number of services: black line $=1$; dotted black line $=2$; solid gray line $=3$, dotted gray line $=4$, dashed black line $=\geq 5$.
Considering the odds ratios for calving season, conception rate, and BRD incidence, it could be concluded that abortion had the strongest effect on survivorship, closely followed by conception rate before first calving and BRD incidence, with calving season having the weakest effect. For continuous variables, based on the coefficient of determination, ADG between 12 and 65 $\mathrm{d}$ of life had a stronger effect on survivorship to second lactation than average AFC.

\section{CONCLUSIONS}

The results from this study show potential to forecast future heifer survivability to second lactation based on ADG early in life (first $2 \mathrm{mo}$ ), incidence of respiratory processes, reproductive performance (conception and abortion rates), and AFC. The integration of survival probabilities for each replacement heifer might help in maximizing the success rate of culling decisions in both cows and heifers.

\section{ACKNOWLEDGMENTS}

Authors are grateful to Rancho Las Nieves for the meticulous data recording efforts and to Subdirección General de Explotaciones y Sistemas de Trazabilidad de los Recursos Agrícolas y Ganaderos from the Ministry of Environment, and Rural and Marine Areas of the Spanish government for providing mortality data. Partial funding from Centro para el Desarrollo Tecnológico Industrial through the project IDI-20080836 is acknowledged.

\section{REFERENCES}

Britney, J. B., S. W. Martin, J. B. Stone, and R. A. Curtis. 1984. Analysis of early calfhood health status and subsequent dairy herd survivorship and productivity. Prev. Vet. Med. 3:45-52.

Congleton, W. R. Jr. 1988. Dairy cow culling decision. 3. Risk of culling on predicted income (an application of Bayes criterion). J. Dairy Sci. 71:1916-1925.

Crawley, M. J. 2007. Page 801 in The R Book. John Wiley \& Sons Ltd., West Sussex, UK.

Donovan, G. A., L. Badinga, R. J. Collier, C. J. Wilcox, and R. K. Braun. 1986. Factors influencing passive transfer in dairy calves. J. Dairy Sci. 69:754-759.

Ettema, J. F., and J. E. P. Santos. 2004. Impact of age at calving on lactation, reproduction, health, and income in first-parity Holsteins on commercial farms. J. Dairy Sci. 87:2730-2742.

Fetrow, J. 1988. Culling dairy cows. Page 102 in Proc. 20th Annu. Am. Assoc. Bovine Pract. Conv., Phoenix, AZ. Frontier Printers, Inc., Stillwater, OK.

Gardner, R. W., L. W. Smith, and R. L. Park. 1988. Feeding and management of dairy heifers for optimal lifetime productivity. J. Dairy Sci. 71:996-999.

Hare, E., H. D. Normand, and J. R. Wright. 2006. Survival rates and productive herd life of dairy cattle in the United States. J. Dairy Sci. 89:3713-3720.

Lehenbauer, T. W., and J. W. Oltjen. 1998. Dairy cow culling strategies: Making economical culling decisions. J. Dairy Sci. 81:264271 . 
Lin, C. Y., A. J. McAllister, T. R. Batra, A. J. Lee, G. L. Roy, J. A. Vesely, J. M. Wauthy, and K. A. Winter. 1988. Effects of early and late breeding of heifers on multiple lactation performance of dairy cows. J. Dairy Sci. 71:2735-2743.

Pinedo, P. J., and A. De Vries. 2010. Effect of days to conception in the previous lactation on the risk of death and live culling around calving. J. Dairy Sci. 93:968-977.

Rizopoulos, D. 2010. JM: An R package for the joint modelling of longitudinal and time-to-event data. J. Stat. Softw. 35:1-33.
Rossini, K. 2004. Effects of calfhood respiratory and digestive disease on calfhood morbidity and first lactation production and survival rates. MS Thesis. Virginia Tech Univ., Blacksburg.

Shapiro, S. S., and M. Wilk. 1965. An analysis of variance test for normality. Biometrika 52:591-601.

Van Amburgh, M. E., D. M. Galton, D. E. Bauman, R. W. Everett, D. G. Fox, L. E. Chase, and H. N. Erb. 1998. Effects of three prepubertal body growth rates on performance of Holstein heifers during first lactation. J. Dairy Sci. 81:527-538. 